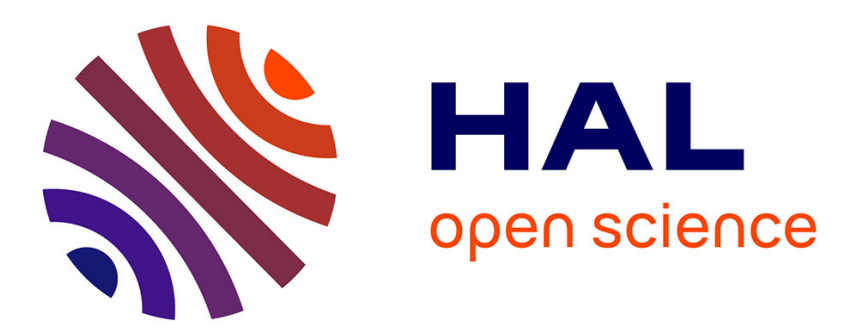

\title{
Polynomial Chaos Expansion for lifetime assessment and sensitivity analysis of reinforced concrete structures subjected to chloride ingress and climate change
}

Emilio Bastidas-Arteaga, Charbel-pierre El Soueidy, Ouali Amiri, Phu Tho Nguyen

\section{To cite this version:}

Emilio Bastidas-Arteaga, Charbel-pierre El Soueidy, Ouali Amiri, Phu Tho Nguyen. Polynomial Chaos Expansion for lifetime assessment and sensitivity analysis of reinforced concrete structures subjected to chloride ingress and climate change. Structural Concrete, 2020, 10.1002/suco.201900398 . hal02459322

\section{HAL Id: hal-02459322 \\ https://hal.science/hal-02459322}

Submitted on 29 Jan 2020

HAL is a multi-disciplinary open access archive for the deposit and dissemination of scientific research documents, whether they are published or not. The documents may come from teaching and research institutions in France or abroad, or from public or private research centers.
L'archive ouverte pluridisciplinaire HAL, est destinée au dépôt et à la diffusion de documents scientifiques de niveau recherche, publiés ou non, émanant des établissements d'enseignement et de recherche français ou étrangers, des laboratoires publics ou privés. 


\title{
Polynomial Chaos Expansion for lifetime assessment and sensitivity analysis of reinforced concrete structures subjected to chloride ingress and climate change
}

\author{
Emilio Bastidas-Arteaga ${ }^{\mathrm{a}, 1}$, Charbel-Pierre El Soueidy ${ }^{\mathrm{a}}$, Ouali Amiri ${ }^{\mathrm{a}, \mathrm{b}}$, Phu Tho Nguyen ${ }^{\mathrm{a}}$ \\ ${ }^{a}$ Université de Nantes, GeM, Institute for Research in Civil and Mechanical Engineering, CNRS UMR 6183, Nantes, France, 2 Rue de la \\ Houssinière, BP 92208, 44322 Nantes Cedex 3, France \\ ${ }^{\mathrm{b}} I U T$ de Saint-Nazaire, 58 rue Michel Ange 44600 Saint-Nazaire, France
}

\begin{abstract}
Chloride-induced corrosion is one of the main causes leading to the lifetime reduction of reinforced concrete (RC) structures in marine environments or subjected to de-icing salts. Modeling chloride ingress into concrete in a comprehensive way is therefore a crucial task to evaluate corrosion initiation risk and carry out preventive maintenance. Nevertheless, this comprehensive modeling is a challenging task that requires solving simultaneously a set of coupled non-linear partial differential equations. This task becomes more complex if the inherent uncertainties of the process are considered for probabilistic lifetime assessment. The present research aims to assess the probability of corrosion initiation of RC structures. The polynomial chaos expansion (PCE) method is employed to propagate uncertainties in a chloride ingress model requiring significant computational time to perform one deterministic simulation. PCE is also applied to perform a sensitivity analysis to determine which are the more influential random variables in the problem. The proposed methodology is applied to RC structures placed in several locations in France (Brest, Marseille, and Strasbourg) and subjected to realistic environmental conditions including climate change. The results show that the PCE-based model is accurate and efficient for lifetime assessment of RC structures subject to chloride-induced corrosion.
\end{abstract}

Key-words: Reinforced concrete; Chloride ingress; Corrosion; Sensitivity Analysis; Polynomial Chaos Expansion; Climate Change

\section{Introduction}

Chloride-induced corrosion is known to be a major cause of premature degradation for reinforced concrete $(\mathrm{RC})$ structures. According to the results obtained from the project $\mathrm{BRIME}^{1}$, there are $26 \%$, $37 \%, 39 \%$ and $30 \%$ of the concrete highway bridges affected by chloride-induced degradation in Norway, Germany, France and United Kingdom, respectively. Chloride-induced damage results on cross-sectional reduction of steels bars, loss of bonding between steel and concrete and concrete cracking and spalling that will affect the serviceability and safety of RC structures ${ }^{2,3}$. It also can lead to important economic consequences due to additional repair and maintenance operations in RC structures.

\footnotetext{
${ }^{1}$ Corresponding author: E-mail: emilio.bastidas@univ-nantes.fr
} 
For example, Koch et $\mathrm{al}^{4}$ found that the global cost of corrosion is US $\$ 2.5$ trillion (about $3.4 \%$ of the global Gross Domestic Product). Thus, developing robust models for prediction and strategies for periodic inspection and maintenance plays a significant role in enabling target reliabilities to be met over a period of continued service ${ }^{5-8}$.

Chloride penetrates into concrete by different mechanisms such as diffusion, convection, migration, absorption, permeation, and thermo-diffusion ${ }^{9,10}$. The mechanism of chloride ingress in sound concrete, and therefore the time to corrosion initiation, could be influenced by: (i) the evolution of concrete properties with time, (ii) weather conditions, (iii) exposure zones (submerged, tidal, splash, salt spray and deicing salts), and (iii) evolution in time of surface chloride concentration. Indeed several studies have shown that chloride penetration is highly affected by weather conditions (temperature and humidity) including climate change. For example, climate change can lead to lifetime reductions ranging from $2 \%$ to $18 \%$ for RC structures subjected to continental, tropical and oceanic weather conditions ${ }^{11-}$ 13 .

The time to corrosion initiation can be considered as a primordial index to assess durability performance of RC structures ${ }^{14}$. Estimation of corrosion initiation time in RC structures is crucial for minimizing both maintenance costs and failure risks ${ }^{11}$. Simplified chloride ingress models based on an error function approximation of the Fick's law diffusion model are useful to assess the corrosion initiation time with a low computational $\cos ^{15}$. However, these simplified models cannot represent accurately chloride ingress under real (complex) exposure conditions. Numerical chloride ingress models take into consideration more interactions among transfer phenomena (e.g., chloride ingress mechanisms, water activity, and thermo-gradient transfer, etc.). Nevertheless its relatively high computational cost poses a serious problem to estimate corrosion initiation time. In particular, when lifetime assessment should be improved to include the uncertainties involved in the problem ${ }^{16,17}$.

Nguyen et $\mathrm{al}^{18}$ recently proposed a chloride ingress model for long-term lifetime assessment of RC structures under realistic climate and exposure conditions. This model is computationally efficient for deterministic computations. However, propagating uncertainties in such a model is still challenging because of the number of random variables involved in the problem and small discretization time step required to account in a comprehensive way for climate variations. To deal with this problem, this paper implements a Polynomial Chaos Expansion (PCE) to develop a so-called chloride ingress surrogate model. PCE has been usefully implemented in other applications for uncertainty propagation and sensitivity analysis purposes with low computational $\operatorname{cost}^{19,20}$.

Within this context, the main objective of this paper is to propose a PCE approximation of the chloride ingress model to perform probabilistic lifetime assessment and sensitivity analysis. The approach will be illustrated with case studies considering various weather and exposure conditions (including climate change) for RC structures placed in France. The paper is organized as follows. Section 2 summarizes the chloride ingress model. Section 3 presents the tools for the probabilistic lifetime assessment (PCE) and sensitivity analysis (Sobol' indices). Section 4 describes the case studies that will be discussed in section 5 to illustrate the construction of the surrogate model, to perform the sensitivity analysis and to assess the corrosion initiation time by considering realistic exposure conditions including climate change.

\section{Chloride ingress model}

Chloride ingress mechanism into concrete structures implies several processes such as diffusion, convection due to capillary adsorption or permeation. In the literature, some researches were carried out 
based on Fick's law ${ }^{21}$. However, these models are valid under the following assumptions ${ }^{9}:$ a) concrete is saturated (permanently submerged in seawater), b) concrete is homogeneous, c) chloride coefficient diffusion is constant (in time and in space), and d) surface chloride concentration is constant throughout time. Recently, some authors tried to improve the Fick's law based diffusion model ${ }^{22}$. However, these approaches still show limitations when considering environmental conditions ${ }^{15}$. To tackle this problem, an efficient deterministic chloride ingress model which accounts for realistic weather conditions has been recently proposed in the literature ${ }^{18}$. The model takes into account the coupling of three processes which are presented in the following section.

\subsection{Humidity transport}

Humidity transport in concrete can be governed by the following equation:

$$
\frac{\partial W}{\partial t}+\underbrace{\operatorname{div}\left(D_{W} \frac{\partial W}{\partial x}\right)}_{\text {humidity diffusion }}=0
$$

where

$$
D_{W}=\exp \left(\frac{E_{h}}{R} \times\left(\frac{1}{T_{\text {ref }}}-\frac{1}{T}\right)\right) \times\left(-\frac{K_{w} K_{r w}}{\mu_{w}} W \frac{\rho_{w} R_{v} T}{R H}\right) \times \frac{\partial R H}{\partial W}
$$

where $W$ is the water content $\left(\mathrm{m}^{3} / \mathrm{m}^{3}\right)$, div is the divergence operator, $E_{h}$ is the activation energy of moisture transfer process $(\mathrm{J} / \mathrm{mol}), R$ is the gas constant $(8.314 \mathrm{~J} / \mathrm{mol} . \mathrm{K}), T$ is the temperature inside concrete (K), $T_{r e f}$ is the reference temperature equal to $20^{\circ} \mathrm{C}, K_{w}$ is the permeability to water of concrete $\left(\mathrm{m}^{2}\right), K_{r w}$ is the relative permeability to water of concrete $(-), \mu_{w}$ is the water viscosity $(\mathrm{Pa} \times \mathrm{s}), \rho_{w}$ is the density of water $\left(\mathrm{kg} / \mathrm{m}^{3}\right), R_{v}$ is the specific gas constant $(461.89 \mathrm{~J} /(\mathrm{kg} \times \mathrm{K}))$ and $R H$ is the relative humidity inside concrete.

\subsection{Heat transfer}

The heat transfer equation can be written as follows:

$$
\frac{\partial T}{\partial t}-\frac{1}{\rho_{0} \times C_{p}} \times \operatorname{div}(\underbrace{\lambda \operatorname{grad} T}_{\text {conduction }})=0
$$

where

$$
\lambda=\left\{\begin{array}{cl}
1.5 & \text { if } T<-4^{\circ} \mathrm{C} \\
\lambda_{\text {ref }} \times\left(0.244\left(\frac{W}{\epsilon}-1\right)+1\right) \times\left(0.0015\left(T-T_{\text {ref }}\right)+1\right) & \text { if } T \geq-4{ }^{\circ} \mathrm{C}
\end{array}\right.
$$

where $\lambda_{\text {ref }}$ is the reference concrete heat conductivity $\left(\mathrm{W} /\left(\mathrm{m} \times{ }^{\circ} \mathrm{C}\right)\right)$ measured for a given temperature e.g., $20^{\circ} \mathrm{C}, \rho_{0}$ is the density of concrete $\left(\mathrm{kg} / \mathrm{m}^{3}\right), C_{p}$ is the effective heat specific of concrete $\left(\mathrm{J} /\left(\mathrm{kg} \times{ }^{\circ} \mathrm{C}\right)\right)$, grad is the gradient operator, $\epsilon$ is the porosity of concrete (-) and $\lambda$ is the heat conductivity of concrete $\left(\mathrm{W} /\left(\mathrm{m} \times{ }^{\circ} \mathrm{C}\right)\right)$ that depends on the weather conditions and material properties.

\subsection{Chloride transfer}

Chloride transfer is governed by diffusion and convection due to capillary pressure or permeation. It can be expressed as follows: 


$$
\frac{\partial\left(W C_{f}\right)}{\partial t}+\frac{\partial C_{b}}{\partial C_{f}} \frac{\partial C_{f}}{\partial t}-\operatorname{div}(\underbrace{D_{e} W \operatorname{grad} C_{f}}_{\text {diffusion }}+\underbrace{C_{f} D_{W} \operatorname{grad} W}_{\text {convection }})=0
$$

where $C_{f}$ is the free chloride concentration ( $\mathrm{mol} / \mathrm{m}^{3}$ solution), $C_{b}$ is the bound chloride concentration ( $\mathrm{mol} / \mathrm{m}^{3}$ concrete) (see equation (11)), $D_{e}$ is the chloride coefficient diffusion $\left(\mathrm{m}^{2} / \mathrm{s}\right)$ which depends on the temperature, the aging factor, the water content, and the chloride concentration and $D_{w}$ is obtained from equation (2). $\mathrm{D}_{\mathrm{e}}$ can be expressed as follows:

$$
D_{e}=D_{C l} \times f_{1}(T) \times f_{2}(t) \times f_{3}(W) \times f_{4}\left(C_{f}\right)
$$

where $D_{C l}$ is the reference diffusion coefficient measured at standard conditions, $f_{1}(T)$ is a function that takes into account the effect of the temperature:

$$
f_{1}(T)=\exp \left(\frac{E_{a}}{R} \times\left(\frac{1}{T_{\text {ref }}}-\frac{1}{T}\right)\right)
$$

where $E_{a}$ is the activation energy of chloride transfer process. $f_{2}(t)$ is a function that considers the effect of concrete aging:

$$
f_{2}(t)=\left(\frac{t_{r e f}}{t}\right)^{m_{a g e}}
$$

where $t_{r e f}=28$ days is the time of exposure at which $D_{C l}$ has been measured, $t$ is the actual exposure time (days) and $m_{\text {age }}$ the age factor (-). $f_{3}(W)$ is a function accounting for the moisture content dependence ${ }^{23}$ :

$$
f_{3}(W)=\left(\frac{W}{\epsilon}\right)^{\frac{7}{3}}
$$

$f_{4}\left(C_{f}\right)$ is a function that considers chloride concentration effect on chloride diffusion process ${ }^{24}$ :

$$
f_{4}\left(C_{f}\right)=1-k_{\text {ion }} \times\left(C_{f}\right)^{m_{\text {ion }}}
$$

where $C_{f}$ is the free chloride concentration ( $\mathrm{kg} / \mathrm{kg}$ concrete), $k_{i o n}$ and $m_{\text {ion }}$ are empirical parameters ( $k_{\text {ion }}$ $\left.=8.33, m_{i o n}=0.5\right)^{25}$.

In order to describe the chloride binding, we use the Langmuir isotherm which is adapted to concrete ${ }^{26,27}$ :

$$
C_{b}=\frac{\alpha C_{f}}{1+\beta C_{f}}
$$

where $\alpha$ and $\beta$ are two parameters estimated experimentally.

The set of non-linear equations (1)-(11) are solved numerically using the finite volume method under some specific initial and boundary conditions ${ }^{25}$.

\section{Probabilistic analysis}

\subsection{Probability of corrosion initiation}

Corrosion initiates when the free chloride concentration at the reinforcement bars estimated with equation (5) exceeds a threshold value $C_{c r t}$. The failure can therefore be defined in terms of the corrosion initiation time $t_{\mathrm{ini}}$ and the associated limit state function reads: 


$$
g(\mathbf{X}, t)=t_{\text {ini }}(\mathbf{X})-t \leq 0
$$

where $\mathbf{X}=\left\{X_{1}, \ldots, X_{d}\right\}$ is the vector of the input random variables of size $d$ considered in the ingress model. Denoting by $f_{\mathbf{X}}(\mathbf{x})$ the joint probability density function of $\mathbf{X}$, the probability of failure at any instant $t$ can be therefore calculated as the integral of $f_{\mathbf{X}}(\mathbf{x})$ in the failure domain:

$$
P_{\mathrm{f}}(t)=\operatorname{Prob}(g(\mathbf{X}, t) \leq 0)=\int_{\{\mathbf{x}: g(\mathbf{x}, t) \leq 0\}} f_{\mathbf{X}}(\mathbf{x}) d \mathbf{x}
$$

It is clear from equation (13) that the integration domain is implicitly defined which renders the analytical computation of the probability of failure cumbersome. Classical reliability methods may be used such as Monte-Carlo, Importance-Sampling and FORM. However, it is shown by Damrongwiriyanupap et $\mathrm{al}^{25}$ that a maximum discretization step of 6 hours is needed when dealing with realistic RC structures submitted to weather conditions. This discretization step is very small compared to the lifespan of civil engineering structures, which makes the ingress model computationally ponderous. The burden is even greater for long-term reliability analysis where repeated calls to the chloride ingress model are needed as in the case of classical reliability methods. In the next section, a surrogate-based approach is proposed which allows to perform both probabilistic and sensitivity analysis for long-term lifetime assessments.

\subsection{Polynomial chaos expansions}

We denote by $\mathcal{M}(\mathbf{X})$ the numerical model that represents the chloride ingress mechanism. Due to the uncertainties represented by $\mathbf{X}$, the output of interest $t_{\mathrm{ini}}=\mathcal{M}(\mathbf{X})$ is also random and can be approximated using an orthogonal polynomial basis as follows ${ }^{28}$ :

$$
\hat{t}_{\text {ini }}=\mathcal{M}^{P C E}(\mathbf{X})=\sum_{\mathbf{a} \in \mathcal{A}} c_{\mathbf{a}} \psi_{\mathbf{a}}(\mathbf{X})
$$

where $\mathcal{A}$ is a set of multi-indices $\mathbf{a}=\left\{a_{1}, \ldots, a_{d}\right\},\left\{c_{\mathbf{a}}, \mathbf{a} \in \mathcal{A}\right\}$ are the unknown coefficients to be determined and $\left\{\psi_{\mathbf{a}}, \mathbf{a} \in \mathcal{A}\right\}$ are multivariate polynomials orthonormal with respect to the joint probability density function $f_{\mathbf{X}}(\mathbf{x})$ of $\mathbf{X}$. The set of multi-indices $\mathcal{A}$ is defined as follows:

$$
\mathcal{A}=\left\{\mathbf{a} \in \mathbb{N}^{d},\|\mathbf{a}\|_{\beta}=\left(\sum_{i=1}^{M} a_{i}{ }^{\beta}\right)^{1 / \beta} \leq p\right\}
$$

with $p$ the total degree of the polynomial chaos (PC) expansion. When $\beta=1$, full polynomials of maximum total degree $p$ are retained, whereas a lower value of $\beta$ favors the main effects and low order interactions between input variables.

Once the basis has been specified, the set of unknowns $\mathbf{c}=\left\{c_{\mathbf{a}}, \mathbf{a} \in \mathcal{A}\right\}$ are obtained by minimizing the mean-square error of the polynomial expansion over a set of $N$ realizations of the input vector $\mathcal{X}=$ $\left\{\mathbf{x}^{(1)}, \ldots, \mathbf{x}^{(N)}\right\}$ called the experimental design (ED):

$$
\mathbf{c}=\underset{\mathbf{c} \in \mathbb{R}^{\operatorname{card}(A)}}{\operatorname{argmin}} \frac{1}{N} \sum_{i=1}^{N}\left(\mathcal{M}\left(\mathbf{x}^{(i)}\right)-\mathcal{M}^{P C E}\left(\mathbf{x}^{(i)}\right)\right)^{2}
$$

A sequential strategy has been proposed by Blatman and Sudret ${ }^{29}$ to enhance the efficiency of the PC expansions by disregarding insignificant terms from the set of terms of $\mathcal{A}$. The sparse version is therefore iteratively built by adding one by one the terms from $\mathcal{A}$ and retaining only those significantly 
improving the accuracy of the surrogate model. The algorithm converges when $Q^{2} \geq Q_{t g t}^{2}$, where $Q_{t g t}^{2}$ is a preset target value of the determination coefficient $Q^{2}$ given by:

$$
Q^{2}=1-\sum_{i=1}^{N}\left(\frac{\mathcal{M}\left(\mathbf{x}^{(i)}\right)-\mathcal{M} \mathcal{C}^{P C E}\left(\mathbf{x}^{(i)}\right)}{1-h_{i}}\right)^{2} / \sum_{i=1}^{N}\left(\mathcal{M}\left(\mathbf{x}^{(i)}\right)-\mu_{t_{i n i}}\right)^{2}
$$

where $\mu_{t_{\text {ini }}}=\frac{1}{N} \sum_{i=1}^{N} \mathcal{M}\left(\mathbf{x}^{(i)}\right)$ and $h_{i}$ is the $i^{\text {th }}$ diagonal term of the matrix: $\boldsymbol{\Psi}\left(\boldsymbol{\Psi}^{\prime} \boldsymbol{\Psi}\right)^{-\mathbf{1}} \boldsymbol{\Psi}^{\prime}$, with $\boldsymbol{\Psi}_{i j}=$ $\psi_{j}\left(\mathbf{x}^{(i)}\right)$.

The computational chloride ingress model can therefore be replaced by a surrogate model whose coefficients $\left\{c_{\mathbf{a}}, \mathbf{a} \in \mathcal{A}\right\}$ contain the complete probabilistic information. Indeed the PC expansion being built in an orthonormal space, the statistical moments of the response, particularly the mean and variance are easily derived as follows:

$$
\mu_{t_{\mathrm{ini}}}=\mathrm{E}\left(\mathcal{M}^{P C E}(\mathbf{X})\right)=c_{\mathbf{0}}
$$

and

$$
\sigma_{t_{\text {ini }}}^{2}=\operatorname{Var}\left(\mathcal{M}^{P C E}(\mathbf{X})\right)=\sum_{\substack{\mathbf{a} \in A \\ \mathbf{a} \neq 0}} c_{\mathbf{a}}^{2}
$$

Furthermore since $\hat{t}_{\mathrm{ini}}=\sum_{\mathbf{a} \in \mathcal{A}} c_{\mathbf{a}} \psi_{\mathbf{a}}(\mathbf{X})$ is polynomial and straightforward to evaluate, the probability density function of $t_{\mathrm{ini}}$ and the probability of failure as defined by equation (13) can be easily estimated through an intensive simulation of the surrogate model $\mathcal{M}^{P C E}$.

\subsection{Sensitivity analysis}

The aim of Sensitivity analysis is to quantify how the uncertainty of the model output $t_{\text {ini }}$ is affected by the variability of each input variable $X_{i}$. In this work, a variance-based method based on Sobol's sensitivity indices ${ }^{30}$ is explored. The aim is to decompose the variance of the output as a sum of contribution of the input random variables. In practice, computing sensitivity indices through MonteCarlo simulation requires $2^{d}$ integrals of $\mathcal{M}(\mathbf{X})$ which is computationally prohibitive in our case. On the other hand, when the model is approximated with a PC surrogate, the sensitivity analysis can be performed easily by post-processing the polynomial coefficients of $\mathcal{M}^{P C E}(\mathbf{X})^{19}$.

The Sobol's decomposition of the PC expansion reads:

$$
\begin{aligned}
\mathcal{M}^{P C E}(\mathbf{X})=c_{\mathbf{0}} & +\sum_{i=1}^{d} \sum_{\mathbf{a} \in I_{i}} c_{\mathbf{a}} \psi_{\mathbf{a}}\left(X_{i}\right)+\sum_{1 \leq i_{1} \leq i_{2} \leq d} \sum_{\mathbf{a} \in I_{i_{1}, i_{2}}} c_{\mathbf{a}} \psi_{\mathbf{a}}\left(X_{i_{1}}, X_{i_{2}}\right)+\cdots \\
& +\sum_{1 \leq i_{1} \leq \ldots \leq i_{S} \leq d} \sum_{\mathbf{a} \in I_{i_{1}, \ldots, i_{S}}} c_{\mathbf{a}} \psi_{\mathbf{a}}\left(X_{i_{1}}, \ldots, X_{i_{S}}\right)+\cdots+\sum_{\mathbf{a} \in I_{i_{1}, \ldots, i_{d}}} c_{\mathbf{a}} \psi_{\mathbf{a}}\left(X_{i_{1}}, \ldots, X_{i_{d}}\right)
\end{aligned}
$$

where $I_{i_{1}, \ldots, i_{s}}$ is the set of non-zero indices $\left(i_{1}, \ldots, i_{s}\right) \in \mathcal{A}$.

The first-order sensitivity index $S_{i}$ considers the main effect of each input variable $X_{i}$ considered separately, on the variability of the model response $t_{\text {ini }}$. It can be computed through the coefficients of the polynomial expansion as follows:

$$
S_{i}=\frac{\sum_{\mathbf{a} \epsilon I_{i}} c_{\mathbf{a}}^{2}}{\sigma_{\hat{t}_{i n i}}^{2}}
$$


The overall effect of the input random variable $X_{i}$ may also be assessed by the total sensitivity index $S_{i}^{T}$. This index accounts for both the main effect of $X_{i}$ and its interactions with the other input variables and is given by:

$$
S_{i}^{T}=\frac{\sum_{\mathbf{a} \in I_{i}^{*}} C_{\mathbf{a}}^{2}}{\sigma_{\hat{t}_{i n i}}^{2}}
$$

where $I_{i}^{*}$ denotes the set of all indices with non-zero $i^{\text {th }}$ component.

\section{Case Study definition}

This section describes three case studies that will be considered to illustrate how the PC surrogate model could be implemented for sensitivity analysis and lifetime assessment. Each case study will consider a structure built in 2017 using the same concrete but exposed to three locations in France (Brest, Marseille and Strasbourg, Figure 1) that represent different chloride exposure and weather conditions (including climate change). It is observed in Table 1 that the study cases account for chlorides coming from the seawater and de-icing salts under Atlantic, Mediterranean and continental weather conditions.

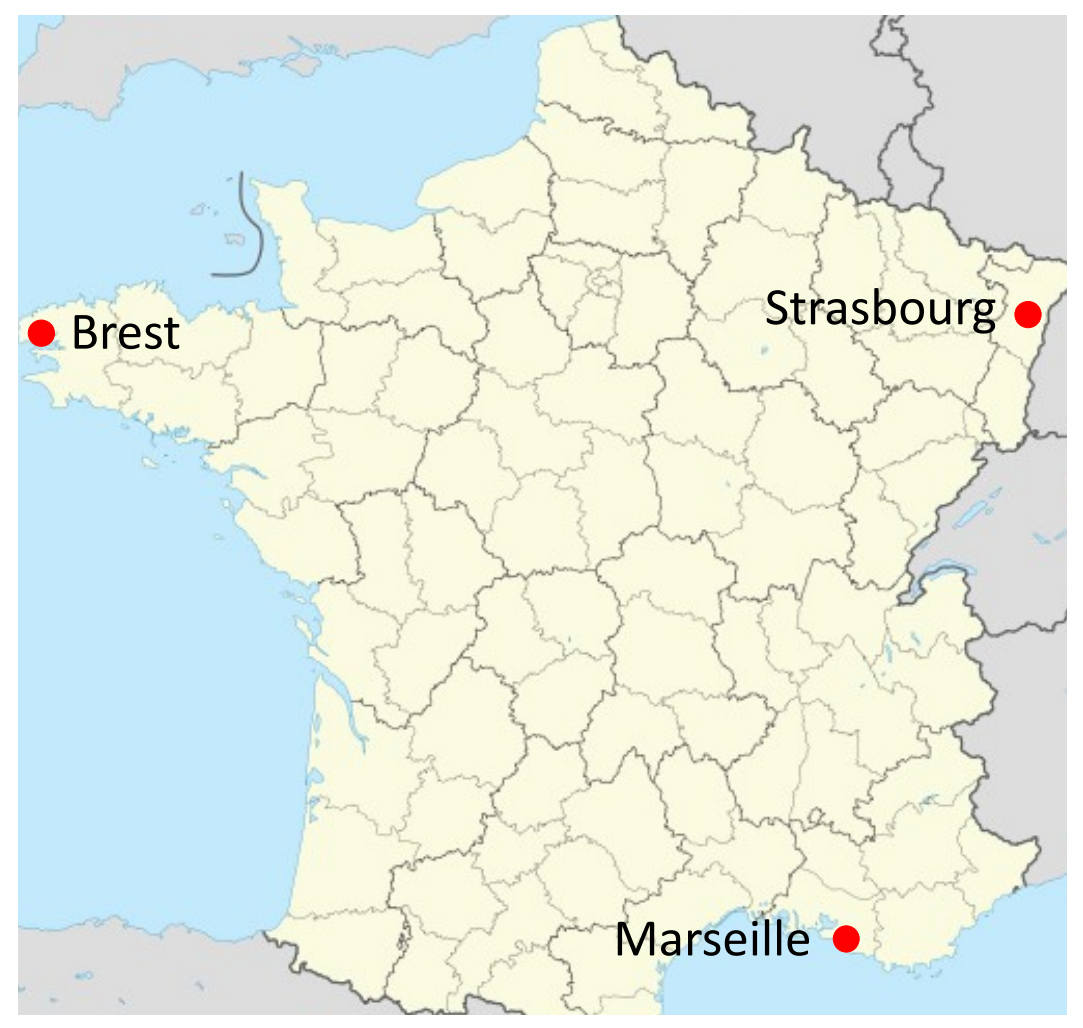

Figure 1: Studied locations. 
Table 1: Summary of chloride exposure and weather conditions for the studied locations

\begin{tabular}{llll}
\hline Location & Chloride exposure & $\begin{array}{l}\text { Surface chloride } \\
\text { concentration }\end{array}$ & Weather conditions \\
\hline Brest & $\begin{array}{l}\text { Tidal cycles: wetting (6h) and drying } \\
\text { (18h) per day }\end{array}$ & $\begin{array}{l}17.75 \mathrm{~kg} / \mathrm{m}^{3} \text { water during the } \\
\text { immersion period (high tide) } \\
\text { and } 0 \text { during the low tide }\end{array}$ & $\begin{array}{l}\text { Cold and humid } \\
\text { Atlantic west climate }\end{array}$ \\
Marseille & $\begin{array}{l}\text { Salt spray from sea chlorides mixed in } \\
\text { the humid air. The surface chloride } \\
\text { concentration is constant during the } \\
\text { structural lifetime }\end{array}$ & $\begin{array}{l}\text { Hot and dry } \\
\text { De-icing salts applied during a winter } \\
\text { period of 5 months (from October to }\end{array}$ \\
Strasbourg \\
$\begin{array}{l}\text { February). This cold period length was } \\
\text { assumed based on recorded weather data }\end{array}$
\end{tabular}

Climate conditions (temperature and relative humidity) will be used as boundary conditions for assessment of the probability of corrosion initiation using the deterioration model described in Section 2. Figure 2 gives the annual values of air temperature and relative humidity for each location and climate change scenario. It is observed that the structures will be exposed to more or less hot and wet climates if climate change effects are neglected (Reference case). These local surrounding environmental conditions will produce different probability of corrosion damage even if the same concrete is used to build the structures ${ }^{31,32}$. Two climate change scenarios (RCP 4.5 and RCP 8.5, Figure 2) defined according to the Fifth Assessment Report (AR5) ${ }^{33}$ will be also considered in the analysis. RCP 4.5 and RCP 8.5 respectively represent moderate and pessimist effects of climate change on the future weather ${ }^{34}$. The overall impact of climate change on the future weather of the selected locations was estimated by using data computed by the French general circulation model CNRM-CM5. For locations in a coastal area (Brest and Marseille), the temperature increases until 2100 by $1.5^{\circ} \mathrm{C}$ and $3.5^{\circ} \mathrm{C}$ for the RCP 4.5 and RCP 8.5 scenarios, respectively. The change of the relative humidity is not significant for these locations (Figure 2). For a continental climate such as Strasbourg (Figure 2), the increases of temperature are in the same order of magnitude than for coastal locations but there is a decrease in relative humidity. For Brest it will be considered that the structure will be subjected to the seawater temperature during the immersion. The values of seawater temperature before 2005 are detailed in Nguyen et al ${ }^{18}$ and were obtained from real measurements available in https://donneespubliques.meteofrance.fr for this location will vary between 10 and $20^{\circ} \mathrm{C}$ depending on the season. 


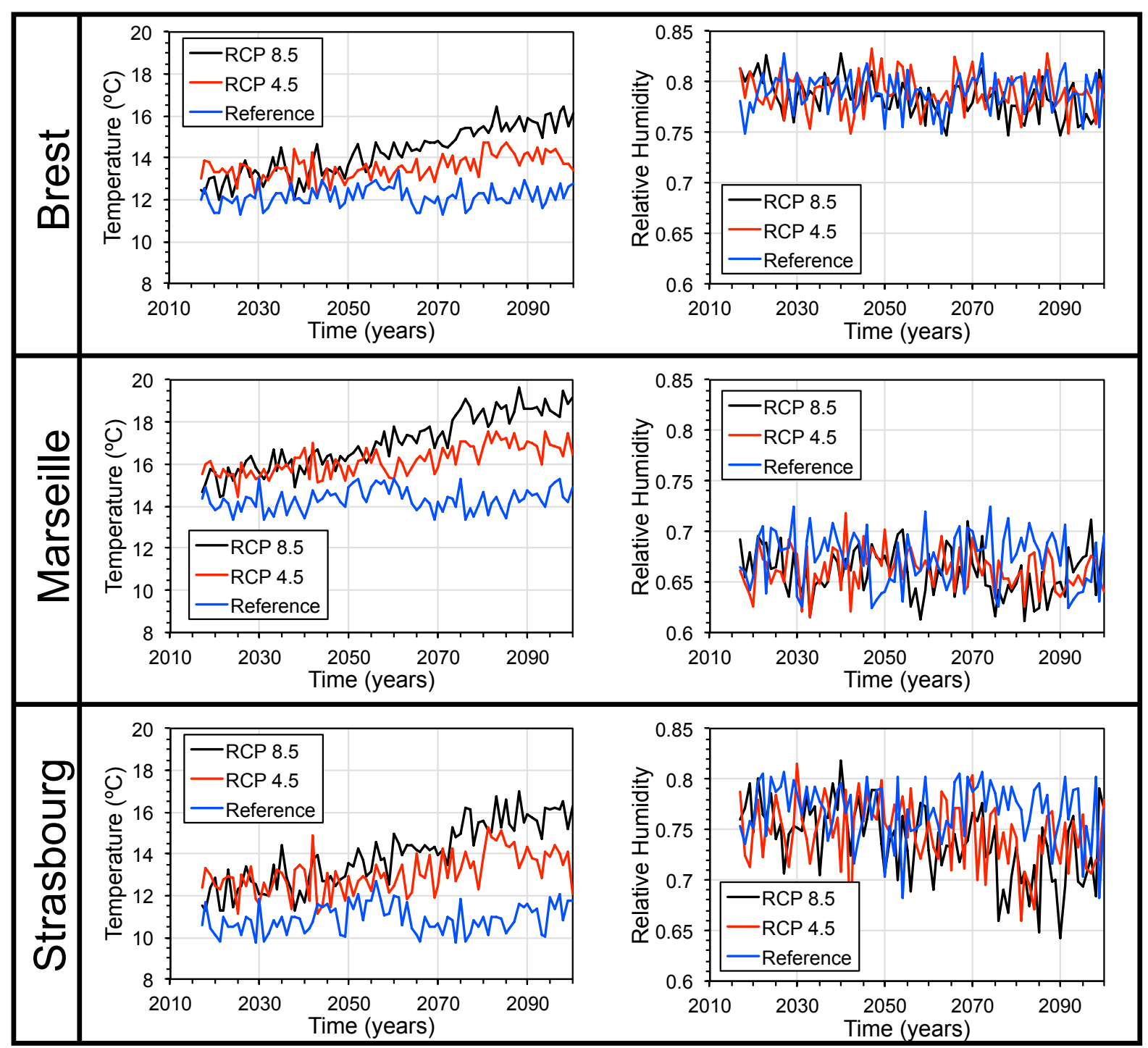

Figure 2: Average climate data (temperature and relative humidity) for the selected locations and climate change scenarios

We also consider that the three RC structures were built using the same concrete that contains $330 \mathrm{~kg} / \mathrm{m}^{3}$ of ordinary Portland cement, $8 \%$ of $\mathrm{C}_{3} \mathrm{~A}$ and $\mathrm{w} / \mathrm{c}=0.5$. This concrete has a characteristic compressive strength, $f^{\prime}{ }_{c k}=35 \mathrm{MPa}$. It is assumed that the hydration period $t_{r e f}$ is equal 28 days. The model parameters (mean and coefficient of variation (COV)) for the considered concrete were determined based on a literature review ${ }^{17,35,36,18}$ and are described in Table 2. It is assumed that all random variables are statistically independent to provide the worst scenario that overestimate deterioration consequences. Real data is required to estimate correlations between the parameters given in Table 2 and improve deterioration assessment. 
Table 2: Deterministic and probabilistic input parameters ${ }^{17,35,36,18}$

\begin{tabular}{|c|c|c|c|c|}
\hline Parameter & Unit & Mean & $\mathrm{COV}$ & Distribution \\
\hline Concrete cover depth, $X_{a c}$ & $\mathrm{~m}$ & 0.05 & 0.25 & Beta $[0.04 ; 0.1]$ \\
\hline Concrete permeability to water, $K_{w}$ & $\mathrm{~m}^{2}$ & $3.4 \times 10^{-21}$ & 0.2 & Lognormal \\
\hline Activation energy for humidity transport, $E_{h}$ & $\mathrm{~J} / \mathrm{mol}$ & 30,750 & 0.15 & Uniform $[22,500 ; 39,000]$ \\
\hline Water viscosity, $\mu_{w}$ & $\operatorname{Pa} \times s$ & $1 \times 10^{-3}$ & $-^{\mathrm{a}}$ & $-{ }^{\mathrm{a}}$ \\
\hline Concrete porosity, $\epsilon$ & - & 0.12 & $-^{\mathrm{a}}$ & $-^{\mathrm{a}}$ \\
\hline Reference concrete thermal conductivity, $\lambda_{\text {ref }}$ & $\mathrm{W} / \mathrm{m}^{\circ} \mathrm{C}$ & 2.5 & 0.2 & Beta $[1.4 ; 3.6]$ \\
\hline Concrete heat capacity, $C_{p}$ & $\mathrm{~J} / \mathrm{kg}^{\circ} \mathrm{C}$ & 1,000 & 0.1 & Beta $[840 ; 1,170]$ \\
\hline Concrete density, $\rho_{0}$ & $\mathrm{~kg} / \mathrm{m}^{3}$ & 2,400 & 0.04 & Normal $^{b}$ \\
\hline Chloride threshold concentration, $C_{c r t}$ & $\%$ cem. wt. & 0.5 & 0.15 & Normal $^{b}$ \\
\hline Chloride coefficient of diffusion, $D_{c l}$ & $\mathrm{~m}^{2} / \mathrm{s}$ & $3 \times 10^{-11}$ & 0.2 & Lognormal \\
\hline Activation energy for chloride transfer, $E_{a}$ & $\mathrm{~J} / \mathrm{mol}$ & 41,800 & 0.1 & Beta $[32,000 ; 44,600]$ \\
\hline Aging factor, mage & - & 0.15 & 0.15 & Beta $[0 ; 1]$ \\
\hline Surface chloride concentration, $C_{S}$ & $\mathrm{~kg} / \mathrm{m}^{3}$ & Table $1^{\mathrm{c}}$ & 0.2 & Lognormal \\
\hline Langmuir isotherm parameter, $\alpha$ & $\mathrm{m}^{3}$ sol. $/ \mathrm{m}^{3}$ conc. & 0.38 & $-^{\mathrm{a}}$ & $-^{\mathrm{a}}+$ \\
\hline Langmuir isotherm parameter, $\beta$ & $\mathrm{m}^{3} \mathrm{sol} . / \mathrm{mol} \mathrm{Cl}^{-}$ & 0.07 & $-^{\mathrm{a}}$ & $-^{\mathrm{a}}$ \\
\hline \multicolumn{5}{|l|}{${ }^{\mathrm{a} D e t e r m i n i s t i c}$} \\
\hline
\end{tabular}

\section{Results and discussions}

This section starts illustrating for one location how to construct a PCE surrogate model. The second part is focused on a sensitivity analysis based on Sobol's estimates. The last part illustrates the use of PCE approximation for lifetime assessment for all the selected locations including climate change effects.

\subsection{Construction of the surrogate model}

Let us consider as an illustrative example the case of a RC structure located in the Mediterranean city of Marseille. The structure is studied over 150 years throughout which it would be subject to corrosion induced mainly by salt spray. A single deterministic run of the chloride ingress model needs about 10 minutes using a workstation (processor: $2.2 \mathrm{GHz}, 30 \mathrm{MB}$ cache, 12 cores; memory: $16 \mathrm{~GB}$ ). It is thus clear that using classical approaches for reliability and sensitivity analyses is unaffordable here since this would require an important number of calls to the deterministic model. We aim therefore to compute the PC expansion of the output of the chloride ingress model $t_{i n i}$ which depends on the input random vector $\boldsymbol{X}=\left\{c, E_{h}, K_{w}, C_{c r t}, \rho_{0}, C_{p}, \lambda_{\text {ref }}, C_{s}, D_{\text {clref }}, E_{a}, m_{a g e}\right\}$. The candidate polynomial basis is determined with $\beta=0.7$ (equation 15) and a preset target accuracy $Q_{t g t}^{2}=0.99$ is chosen (equation 17). Numerical experiments from the literature show that both values achieve a good trade-off between computational efficiency and reliability analysis accuracy.

An initial ED with $N_{S}=1000$ samples is first generated which corresponds to 1000 chloride ingress model evaluations. Extra $N_{\text {new }}=200$ samples are then sequentially added until the prescribed accuracy $Q_{t g t}^{2}$ is reached. The polynomial degree of the PC approximation, the number of basis elements and the determination coefficient are given in Table 3 for different sizes of the ED. It can be observed that the target accuracy is reached for an ED of final size $N_{S}=2000$. The corresponding PC approximation is of order $p=7$ and contains 185 basis elements. Figure 3 compares the exact values of $t_{\text {ini }}$ obtained by the chloride ingress model with the surrogate ones $\hat{t}_{i n i}$ considering the initial $\left(N_{s}=1000\right)$ and final $\left(N_{s}=2000\right)$ experimental designs. It is shown that the accuracy of the surrogate is improved with the number of samples. 
Table 3: Accuracy of the PC approximation depending on the number of simulations

\begin{tabular}{cccc}
\hline$N_{S}$ & $p$ & Size of $\mathcal{A}$ & $Q^{2}$ \\
\hline 1000 & 6 & 150 & 0.9839 \\
1200 & 6 & 122 & 0.9869 \\
1400 & 7 & 174 & 0.9854 \\
1600 & 7 & 198 & 0.9873 \\
1800 & 7 & 229 & 0.9895 \\
2000 & 7 & 185 & 0.9902 \\
\hline
\end{tabular}
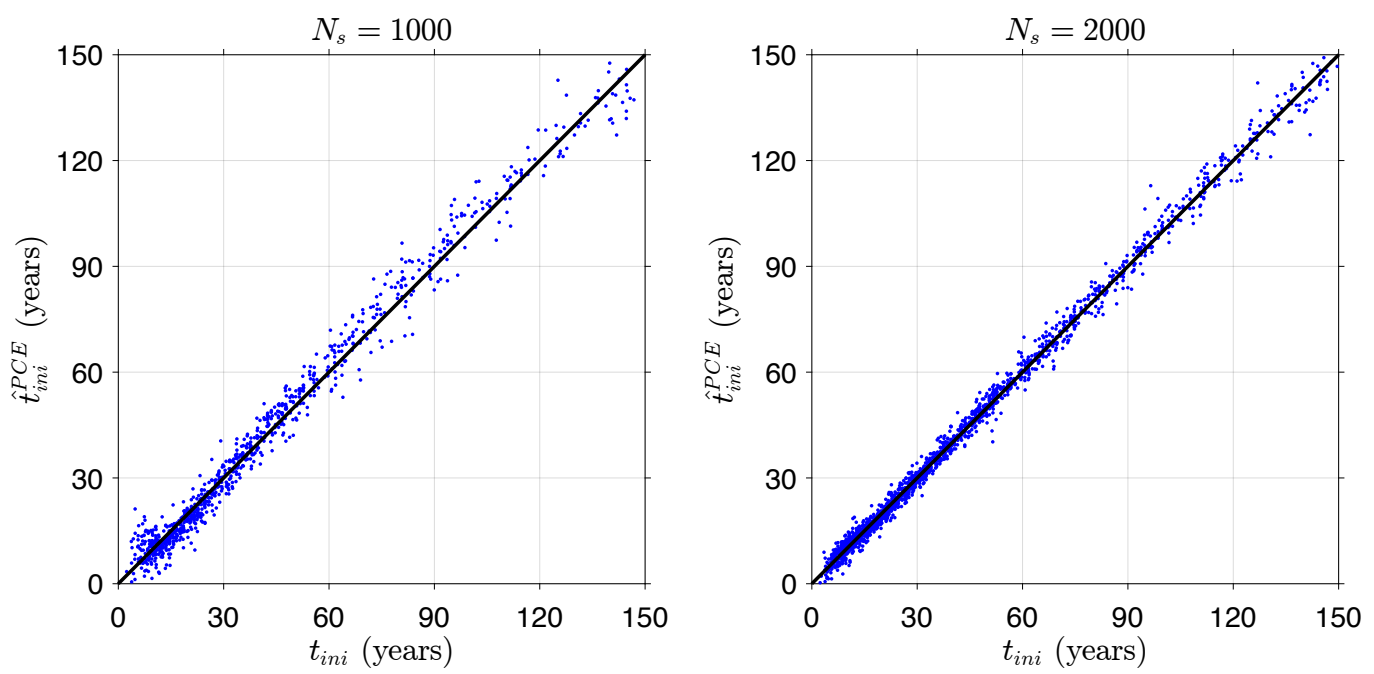

Figure 3: Comparison between values of $t_{\text {ini }}$ obtained from the chloride ingress model and the PCE approximation

Once the PC expansion is defined, statistical analyses become easily affordable by performing MC simulations on the polynomial model. Figure 4 depicts the discrete probability density function (PDF) of the model input $t_{\text {ini }}$ obtained with 2000 samples. It can be concluded that this histogram is well fitted with the continuous function obtained by the surrogate model using $10^{6} \mathrm{MC}$ simulations. It is also noticed that the distribution of $\hat{t}_{\text {ini }}$ is positively skewed with a high coefficient of variation of $104 \%$. It is worth noting here that the shape of the output variable highly affects the size of the ED. The highly non-Gaussian the output is and the more number of samples is needed in order to achieve good accuracy of the surrogate model.

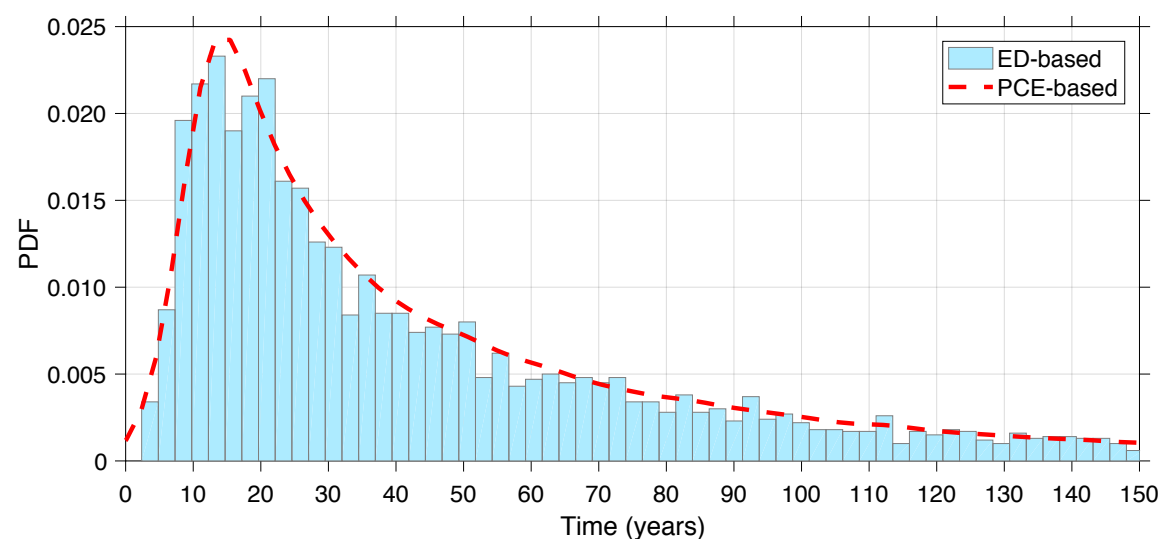

Figure 4: Comparison of discrete probability density functions of the time to corrosion initiation obtained from ED and PCE 


\subsection{Global sensitivity analysis of corrosion initiation to input parameters}

This section aims at determining the more influential random variables when estimating the time to corrosion initiation. The results presented herein consider the study cases described in Section 4 and were determined using a PC approximation with similar accuracy to the indicated in Table 3 for Brest and Strasbourg.

Figure 5 provides the results of the sensitivity analysis based on the total Sobol indices. It is noted that the sensitivity was different for each study case. For RC structures exposed to tidal zone in Brest, chloride comes from the Atlantic Ocean with a constant (deterministic) concentration when the structure is submerged (Table 1). $C_{s}$ is not included in the sensitivity analysis for this location because this parameter is modelled as a deterministic function (see footnote in Table 2) and therefore the output of the model is associated with ten random variables: $K_{w}, D_{c l}, E_{h}, \rho_{0}, C_{c r t}, X_{a c}, \lambda_{r e f}, C_{p}, E_{a}$, and $m_{\text {age. }}$. Among the ten random variables only four have a significant sensitivity: the chloride threshold concentration $C_{c r t}$, the concrete cover $X_{a c}$, the chloride diffusion coefficient $D_{c l}$ and the aging factor $m_{a g e}$ with the following ranking from the most to the less influential: $C_{c r t}, X_{a c}, D_{c l}$, and $m_{a g e}$.
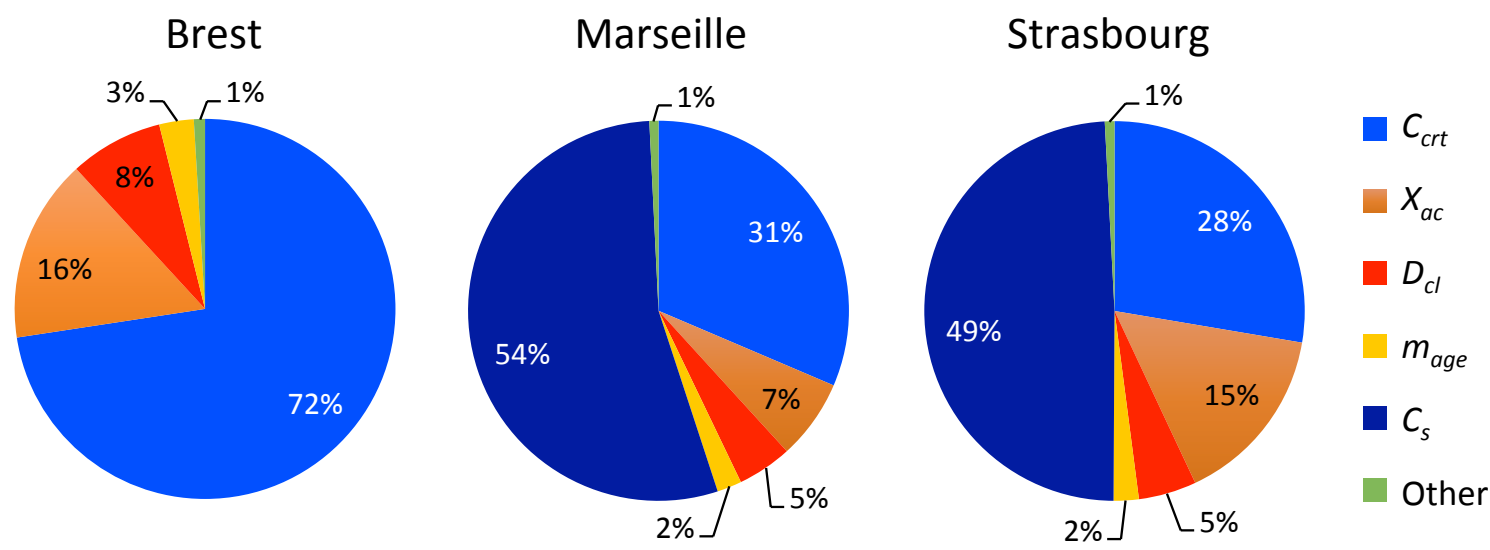

Figure 5: Sensitivity analysis results based on Sobol indices for the reference scenario

For Marseille and Strasbourg, eleven random variables including the ten parameters above-mentioned and $C_{s}$ are considered. Figure 5 shows that five random variables are the more influencing for these locations with the following ranking from the most to the less influential: $C_{s}, C_{c r t}, X_{a c}, D_{c l}$, and $m_{\text {age. }}$ The surface chloride concentration was the most sensitive parameter in both cases.

The results of this sensitivity analysis are in agreement with other findings reported in the literature as well as with the mechanisms of chloride penetration. For example, Bastidas-Arteaga et a ${ }^{16}$ also found that the surface chloride concentration had a large impact on the probabilistic assessment of the corrosion initiation time. Since the chloride ingress is governed principally by diffusion, it is expected that the chloride diffusion coefficient $D_{c l}$ and the aging factor $m_{a g e}$ become key parameters for lifetime assessment ${ }^{37}$. Finally, as a way of protection against corrosion initiation, the concrete cover was also identified as an influential parameter ${ }^{38}$. Excluding the fact that the chloride concentration was not considered as random variable for Brest, the ranking of importance of the more influential parameters remains similar for all the studied locations in France. Therefore, these results are useful to orientate further research or to help infrastructure decision-makers to identify the most influential parameters where the uncertainty quantification efforts should be addressed to improve lifetime assessment. 


\subsection{Probabilistic assessment of time to corrosion initiation including climate change effects}

The procedure described in section 5.1 was applied to each study case to develop appropriate surrogate models. These surrogates were used to estimate the mean and standard deviation of the times to corrosion initiation provided in Table 4. The results in this table indicate that the mean time to corrosion initiation depends on the chloride exposure and weather conditions even if the RC structure is built using the same material and concrete cover. Similar results were also reported in other studies ${ }^{11,13,31,39}$. As expected, the smaller time to corrosion initiation corresponds to structures placed in Brest and subjected to tidal cycles that will accelerate the chloride ingress process. Times to corrosion initiation in the range of 49 to 61 years were estimated for Marseille and Strasbourg. It is also noted that propagating uncertainties in the chloride ingress models generates larger standard deviations that correspond to coefficients of variation in the range 0.9 to 1.08 for all the studied cases. This higher variability in the response justifies the use of an efficient tool for probabilistic lifetime assessment such as the PC in order to consider these uncertainties for optimizing maintenance procedures.

Table 4 also includes the results concerning the effects of climate. It is noted that for all cases climate change induces a reduction of the mean and standard deviation of the time to corrosion initiation. In general, the reductions are larger for the mean values and vary in the range $[3 \%, 10 \%]$ and $[4 \%, 14 \%]$ for the RCP 4.5 and RCP 8.5 scenarios, respectively. These results are in the order of magnitude of those reported by Bastidas-Arteaga et $\mathrm{al}^{16}$. The minor climate change impacts were found for Brest. This is mainly explained by two reasons. First, corrosion initiation will occur in a short-term (in average 30 years) and as noted in Figure 2 the effects of climate change on temperature will be appreciable after 2060; thus, the structures will be mostly subjected to a weather similar to the reported for the reference case. Second, as mentioned in section 4, during the immersion cycles the concrete is exposed to the seawater temperature that is less affected by climate change.

Table 4: Mean and standard deviation of the time to corrosion initiation for the considered locations including climate change effects

\begin{tabular}{lccccc}
\hline Exposure condition & $\begin{array}{c}\text { Climate } \\
\text { scenario }\end{array}$ & $\begin{array}{c}\text { Mean } \\
\text { (years) }\end{array}$ & $\begin{array}{c}\text { St. Dev. } \\
\text { (years) }\end{array}$ & $\begin{array}{c}\text { Reduction of } \\
\text { the mean }\end{array}$ & $\begin{array}{c}\text { Reduction of } \\
\text { the St. Dev. }\end{array}$ \\
\hline \multirow{3}{*}{ Brest (Tidal zone) } & Reference & 31.5 & 29.9 & - & - \\
& RCP 4.5 & 30.6 & 29.6 & $3.0 \%$ & $1.0 \%$ \\
& RCP 8.5 & 30.4 & 29.5 & $3.6 \%$ & $1.3 \%$ \\
\hline \multirow{3}{*}{ Marseille (Salt spray) } & Reference & 61.2 & 61.2 & - & - \\
& RCP 4.5 & 55.3 & 58.5 & $9.7 \%$ & $4.5 \%$ \\
& RCP 8.5 & 53.1 & 57.2 & $13.3 \%$ & $6.6 \%$ \\
\hline \multirow{3}{*}{ Strasbourg (Deicing salts) } & Reference & 55.1 & 50.8 & - & - \\
& RCP 4.5 & 51.1 & 48.0 & $7.3 \%$ & $5.7 \%$ \\
& RCP 8.5 & 49.0 & 46.9 & $11.1 \%$ & $7.7 \%$ \\
\hline
\end{tabular}

\section{Conclusions}

This work presented a probabilistic model for assessing the long-term reliability of RC structures subjected to chloride-induced corrosion. The corrosion initiation time is obtained from a deterministic chloride ingress model that combines humidity, heat and chloride transfer. To reduce the cost of the probabilistic analysis, PC expansions are implemented to assess a surrogate function of the chloride ingress model from a sample evaluation set. 
The first results showed that an accurate surrogate of the chloride transfer model can be obtained with a reduced number of output evaluations. Moreover and because the PC surrogate is fast to evaluate, the PDF of the corrosion initiation time is efficiently estimated. The second outputs concerned a sensitive analysis based on Sobol's indices. This analysis indicated that the sensitivity is different for each location but the more influencing parameters are $C_{s}, C_{c r t}, X_{a c}, D_{c l}$, and $m_{a g e}$. Finally, surrogate models were used to estimate the effects of climate change on the time to corrosion initiation for several locations and scenarios. As expected, the time to corrosion initiation depends on environmental and exposure conditions that are specific for each case. It was also found that climate change could accelerate corrosion initiation from 3 to $13 \%$. Climate change could also have an effect on the critical chloride concentration for corrosion initiation $C_{c r t}$. Further research concerning the effects of environmental conditions (temperature and relative humidity) on $C_{c r t}$ is necessary to update the above-mentioned climate change consequences on corrosion initiation.

\section{Acknowledgements}

The authors would like to acknowledge the support of the 'Pays de la Loire' region through the project RI-ADAPTCLIM 'International Network on Risk Assessment and Climate Adaptation for Infrastructure and Buildings'.

\section{References}

1 Woodward TRL, Cullington DW, Daly AF, Vassie PR, Haardt P, Kashner R. Bridge Management in Europe (BRIME)-Deliverable D14-Fina report. 2001.

2 Imperatore S, Rinaldi Z, Spagnuolo S. Experimental investigations on the effects of the steel rebar corrosion at structural level. Struct Concr 2019;n/a: https://doi.org/10.1002/suco.201900246.

3 Bezuidenhout SR, Zijl GPAG van. Corrosion propagation in cracked reinforced concrete, toward determining residual service life. Struct Concr 2019;n/a: https://doi.org/10.1002/suco.201800275.

4 Koch G, Varney J, Thompson N, Moghissi O, Gould M, Payer J. International Measures of Prevention, Application, and Economics of Corrosion Technologies Study. NACE International IMPACT Report, Houston, TX 77084; 2016.

5 Clifton JR. Predicting the Service Life of Concrete. ACI Mater J 1993:611-7.

6 Mori Y, Ellingwood BR. Reliability-Based Life Prediction of Structures Degrading Due to Environment and Repeated Loading.

7 Bastidas-Arteaga E, Bressolette Ph, Chateauneuf A, Sánchez-Silva M. Probabilistic lifetime assessment of RC structures under coupled corrosion-fatigue processes. Struct Saf 2009;31:84-96. https://doi.org/10.1016/j.strusafe.2008.04.001.

8 Bastidas-Arteaga E, Schoefs F. Sustainable maintenance and repair of RC coastal structures. Proc Inst Civ Eng - Marit Eng 2015;168:162-73. https://doi.org/10.1680/jmaen.14.00018.

9 Tuutti K. Corrosion of steel in concrete. Swedish Cement and Concrete Research Institute; 1982.

10 Martin-Pérez B. Service life modeling of R.C. highway structures exposed to chlorides. PhD Thesis, Toronto, Canada: University of Toronto; 1999; 1999.

11 Bastidas-Arteaga E, Stewart MG. Damage risks and economic assessment of climate adaptation strategies for design of new concrete structures subject to chloride-induced corrosion. Struct Saf 2015;52, Part A:40-53. https://doi.org/10.1016/j.strusafe.2014.10.005.

12 Wang X. Analysis of climate change impacts on the deterioration of concrete infrastructure. Australian Policy Online. 2011.

13 Bastidas-Arteaga E. Reliability of Reinforced Concrete Structures Subjected to Corrosion-Fatigue and Climate Change. Int J Concr Struct Mater 2018;12:. https://doi.org/10.1186/s40069-018-0235$\mathrm{x}$. 
14 Kirkpatrick TJ, Weyers RE, Sprinkel MM, Anderson-Cook CM. Impact of specification changes on chloride-induced corrosion service life of bridge decks. Cem Concr Res 2002;32:1189-97. https://doi.org/10.1016/S0008-8846(02)00760-3.

15 Marchand J, Samson E. Predicting the service-life of concrete structures - Limitations of simplified models. Cem Concr Compos 2009;31:515-21. https://doi.org/10.1016/j.cemconcomp.2009.01.007.

16 Bastidas-Arteaga E, Chateauneuf A, Sánchez-Silva M, Bressolette Ph, Schoefs F. Influence of weather and global warming in chloride ingress into concrete: A stochastic approach. Struct Saf 2010;32:238-49. https://doi.org/10.1016/j.strusafe.2010.03.002.

17 Bastidas-Arteaga E, Schoefs F, Stewart MG, Wang X. Influence of global warming on durability of corroding RC structures: A probabilistic approach. Eng Struct 2013;51:259-66. https://doi.org/10.1016/j.engstruct.2013.01.006.

18 Nguyen PT, Bastidas-Arteaga E, Amiri O, Soueidy C-PE. An efficient chloride ingress model for long-term lifetime assessment of reinforced concrete structures under realistic climate and exposure conditions. Int J Concr Struct Mater 2017. https://doi.org/DOI: 10.1007/s40069-017-0185-8.

19 Blatman G, Sudret B. Efficient computation of global sensitivity indices using sparse polynomial chaos expansions. Reliab Eng Syst Saf 2010;95:1216-29. https://doi.org/10.1016/j.ress.2010.06.015.

20 Deman G, Konakli K, Sudret B, Kerrou J, Perrochet P, Benabderrahmane H. Using sparse polynomial chaos expansions for the global sensitivity analysis of groundwater lifetime expectancy in a multilayered hydrogeological model. Reliab Eng Syst Saf 2016;147:156-69. https://doi.org/10.1016/j.ress.2015.11.005.

21 de la Vega MR, Loureiro JM, Rodrigues AE. Equivalence between Nernst-Planck and "corrected" Fick's law in modeling fixed-bed ion exchange processes. Chem Eng J Biochem Eng J 1996;61:12332. https://doi.org/10.1016/0923-0467(95)03036-0.

22 De Vera G, Climent MA, Viqueira E, Antón C, López MP. Chloride Penetration Prediction in Concrete through an Empirical Model Based on Constant Flux Diffusion. J Mater Civ Eng 2015;27:

23 Buchwald A. Determination of the ion diffusion coefficient in moisture and salt loaded masonry materials by impedance spectroscopy. 3rd Int PhD Symp 2000;vol 2. p 475:

24 Xi Y, Bažant ZP. Modeling chloride penetration in saturated concrete. J Mater Civ Eng 1999;11:5865.

25 Damrongwiriyanupap N, Limkatanyu S, Xi Y, Limkatanyu S, Xi Y. A Thermo-Hygro-Coupled Model for Chloride Penetration in Concrete Structures. Adv Mater Sci Eng 2015;2015:e682940. https://doi.org/10.1155/2015/682940.

26 Sleiman H, Amiri O, Aït-Mokhtar A. Chloride transport in unsaturated cement-based materials. Eur J Environ Civ Eng 2009;13:489-99. https://doi.org/10.1080/19648189.2009.9693125.

27 Tang L, Nilsson L-O. Chloride binding capacity and binding isotherms of OPC pastes and mortars. Cem Concr Res 1993;23:247-253.

28 Xiu D, Karniadakis G. The Wiener--Askey Polynomial Chaos for Stochastic Differential Equations. SIAM J Sci Comput 2002;24:619-44. https://doi.org/10.1137/S1064827501387826.

29 Blatman G, Sudret B. An adaptive algorithm to build up sparse polynomial chaos expansions for stochastic finite element analysis. Probabilistic Eng Mech 2010;25:183-97. https://doi.org/10.1016/j.probengmech.2009.10.003.

30 Sobol' IM. Sensitivity Estimates for Nonlinear Mathematical Models. Math Model Comput Exp 1993;1:407-14.

31 Bastidas-Arteaga E, Stewart MG. Economic assessment of climate adaptation strategies for existing reinforced concrete structures subjected to chloride-induced corrosion. Struct Infrastruct Eng 2016;12:432-49. https://doi.org/10.1080/15732479.2015.1020499.

32 Bastidas-Arteaga E, Stewart MG. Climate Adaptation Engineering: Risks and Economics for Infrastructure Decision-Making. Butterworth-Heinemann; 2019.

33 IPCC. Climate Change 2013: The physical science basis. Contribution of working group I to the fifth assessment report of the intergovernmental panel on climate change 2013.

34 Vuuren DP van, Edmonds J, Kainuma M, Riahi K, Thomson A, Hibbard K, et al. The representative concentration pathways: an overview. Clim Change 2011;109:5. https://doi.org/10.1007/s10584011-0148-z. 
35 Baroghel-Bouny V, Mainguy M, Lassabatere T, Coussy O. Characterization and identification of equilibrium and transfer moisture properties for ordinary and high-performance cementitious materials. Cem Concr Res 1999;29:1225-38. https://doi.org/10.1016/S0008-8846(99)00102-7.

36 Duracrete. Statistical quantification of the variables in the limit state functions, DuraCrete probabilistic performance based durability design of concrete structures. vol. EU - Brite EuRam III. Contract BRPR-CT95-0132, Project BE95-1347/R9. 2000.

37 Zhang J, Lounis Z. Sensitivity analysis of simplified diffusion-based corrosion initiation model of concrete structures exposed to chlorides. Cem Concr Res 2006;36:1312-23. https://doi.org/10.1016/j.cemconres.2006.01.015.

38 Rakotovao Ravahatra N, Bastidas-Arteaga E, Schoefs F, de Larrard T, Duprat F. Probabilistic and sensitivity analysis of analytical models of corrosion onset for reinforced concrete structures. Eur $J$ Environ Civ Eng 2019:1-30. https://doi.org/10.1080/19648189.2019.1591307.

39 de Larrard T, Bastidas-Arteaga E, Duprat F, Schoefs F. Effects of climate variations and global warming on the durability of RC structures subjected to carbonation. Civ Eng Environ Syst 2014;31:153-64. https://doi.org/10.1080/10286608.2014.913033. 